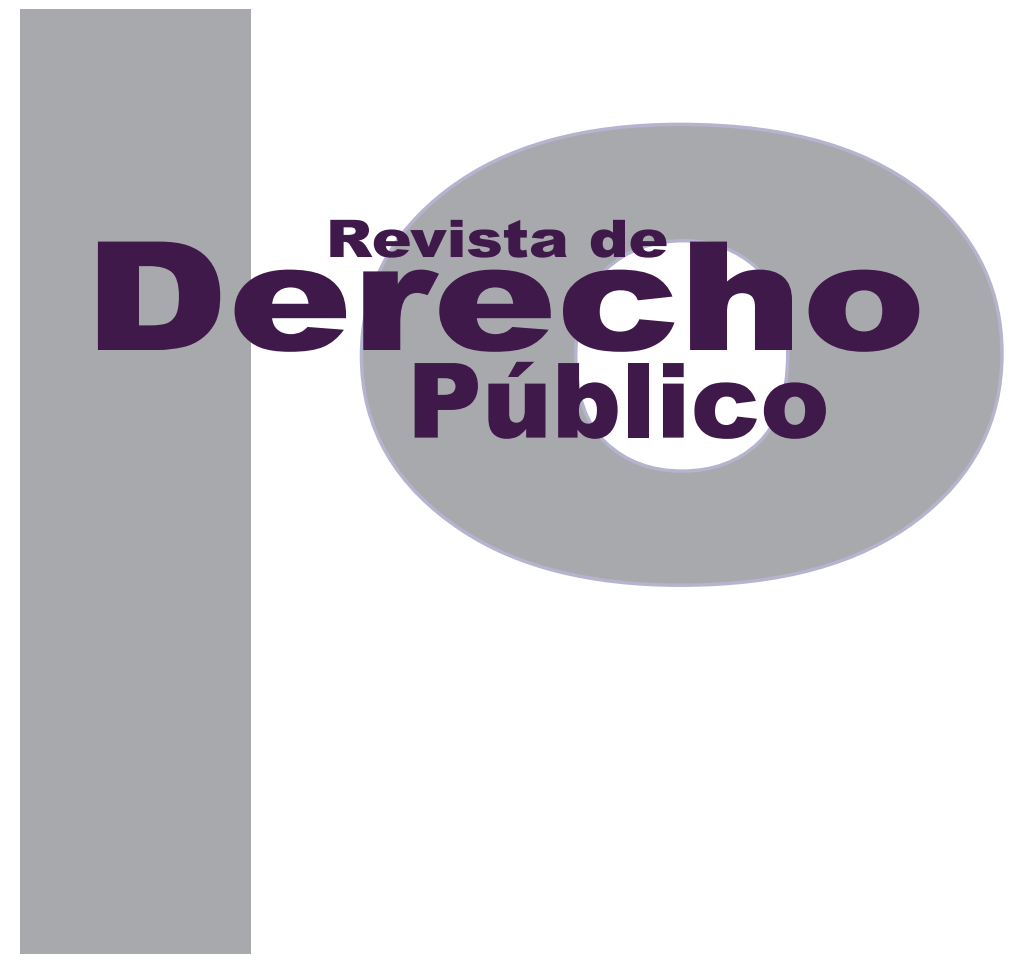

\title{
REFORMAS AL CURRÍCULO Y REGULACIÓN A LA ENSEÑANZA DEL DERECHO: EL CASO DE LA FACULTAD DE DERECHO DE LA UNIVERSIDAD DE LOS ANDES
}

\author{
SERgio IVÁN ANZOLA ROdRígueZ
}

Universidad de los Andes

Facultad de Derecho

Revista de Derecho Público N. ${ }^{\circ} 32$

Enero - Junio de 2014. ISSN 1909-7778 


\title{
Reformas al currículo y regulación a la enseñanza del Derecho: el caso de la Facultad de Derecho de la Universidad de los Andes*
}

\author{
Sergio Iván Anzola Rodríguez**
}

\section{RESUMEN}

Este artículo demuestra cómo los exámenesde Estado de calidad de la educación superior (en adelante ECAES) y los procesos de acreditación han logrado limitar de manera efectiva el proyecto de una enseñanza alternativa del Derecho en la Universidad de los Andes. Al enfocarse en el estudio de las reformas al currículo realizadas entre los años 1997 y 2005 el artículo argumenta que estos mecanismos han logrado que las respuestas a las preguntas qué es el Derecho, cómo se debe enseñar y qué es ser un buen abogado, no dependan de la orientación de cada Facultad en particular, sino que encuentren como única respuesta aquella otorgada por la visión práctica y tradicional del Derecho que tiene la mayoría de
This article shows how State exams created to verify the quality of education and institutional quality accreditation processes, have successfully truncated the project of an alternative way of teaching Law in the Law Faculty of Universidad de los Andes. By studying the reforms to the Law curriculum through 1997 and 2005, the article holds that these mechanisms have implied that answers to questions such as what is Law, how should it be teach, and what does it mean to be a good a Lawyer, do not depend on the particular view of each law Faculty but rather on a traditional and practical view of the legal profession held by the majority of lawyers in Colombia. In light of this, these mechanisms have been able to limit on a subtle but effec-

Cómo citar este artículo: Anzola, S. I. (junio, 2014). Reformas al currículo y regulación a la enseñanza del Derecho: el caso de la Facultad de Derecho de la Universidad de los Andes. Revista de Derecho Público, 32.

Abogado de la Universidad de los Andes (2007), maestría de la Universidad de Helsinki (2009), estudiante de Doctorado en Derecho en la Universidad de los Andes. Correo: si.anzola20@uniandes.edu.co 
profesionales de la disciplina. De esta forma, estos procesos logran limitar de manera efectiva pero sutil el derecho a la autonomía universitaria consagrado en la Constitución Política, truncando cualquier desviación de la visión tradicional y hegemónica que ha caracterizado la enseñanza de esta ciencia.

Palabras Clave: educación legal, currículo, regulación, autonomía universitaria, exámenes de Estado de calidad de la educación superior, procesos de acreditación. tive way the constitutional right that protects the autonomy of universities denying any alternative project that fails to meet the traditional and hegemonic view of the legal profession.

KEY WORDS: legal education, regulation, curriculum, right to autonomy of universities, state exams, quality accreditation processes. 


\section{SUMARIO}

Introducción - I. LA FACULTAD DE DERECHO Y SU ASPIRACIÓN A UNA FORMACIÓN INNOVADORA - II. CONTEXTO DE LA REFORMA DE 1997 - A. Libertad de cátedra y autonomía universitaria III. LA REFORMA AL CURRÍCULO EN 1997 - IV. INTERMEZZO: 1997 - 2005 - V. LA REFORMA EN 2005 - VI. EL CONTEXTO DE LA REFORMA EN 2005 - A. Los deficientes resultados en el ECAES - 1. El ECAES - 2. Los resultados de los ECAES 2003 y 2004 vistos desde la Facultad - B. El proceso de acreditación en 2003 - 1. El sistema de acreditación - 2. Los comentarios de los pares académicos en el proceso de acreditación de 2003 - VII. DE LA REGULACIÓN VERTICAL Y CENTRALIZADA A LA REGULACIÓN HORIZONTAL Y DISPERSA - VIII. CONCLUSIONES - Bibliografía. 
Introducción

Este artículo sostiene que la enseñanza del Derecho en la Facultad de Derecho de la Universidad de los Andes pasó de ser reglamentada por el Estado a través de disposiciones normativas como decretos provenientes de una autoridad centralizada, a ser regulada por mecanismos dispersos y horizontales como los exámenes de Estado de calidad de la educación superior $\left(\right.$ ECAES $^{1}$ ) y los procesos de acreditación, que no son guiados por un "centro" determinado, sino por una autoridad dispersa que no es otra que la visión e identidad práctica y tradicional que tiene la mayoría de los profesores de la disciplina del Derecho. Bajo esta lógica, la autonomía universitaria, garantizada constitucionalmente, viene a ser limitada no por el Estado sino por otros procesos menos formales, pero en todo caso efectivos, en cuanto a imponer una visión del Derecho y de la forma en que este debe ser enseñado. Esta hipótesis será demostrada a través del estudio de las reformas hechas al currículo de la carrera de Derecho en la Universidad de los Andes en 1997 y 2005, así como de los contextos y razones que las guiaron. $\mathrm{Si}$ bien es importante reconocer que los cambios curriculares solo son un componente de la reforma a la enseñanza del Derecho, entre otros aspectos ${ }^{2}$, este artículo se enfocará únicamente en este punto particular de ambas reformas.

1 Desde el primer semestre del año 2012 los exámenes ECAES empezaron a llamarse Pruebas Saber Pro. Este cambio en su nombre no tuvo repercusiones sustanciales, razón por la cual en este artículo se les llamará ECAES.

2
El artículo está estructurado de la siguiente forma: una primera parte que describe la visión transformadora que ha tenido y que aún conserva la Universidad de los Andes y su Facultad de Derecho, en la cual la idea de innovación en la enseñanza es central. La segunda parte presenta el contexto que rodeó y motivó la reforma a la enseñanza del Derecho en la Facultad, en 1997, y explica el concepto de autonomía universitaria que fue uno de sus factores más determinantes. La tercera parte se ocupa de los cambios puntuales realizados al currículo mediante la reforma de 1997 y los problemas que estos buscaban resolver. En la cuarta parte se detallan algunos cambios menores incluidos en el 2004 al currículo que emergió de la reforma de 1997 y se introduce la idea, ya expuesta por otros autores, de que en realidad desde 1997 hubo una ola contrarreformista al interior de la Facultad. La quinta parte empieza por describir puntualmente los cambios al currículo realizados en el año 2005, para pasar luego, en la sexta parte, a explicar el contexto y las razones que llevaron a esos cambios. Este artículo argumenta que las dos razones principales que los motivaron, de acuerdo con los documentos y actas de la Universidad y de la Facultad que soportaron la reforma, fueron los deficientes resultados obtenidos en las primeras versiones de los exámenes ECAES y el proceso de acreditación iniciado en el 2001. Por último, la séptima parte explica cómo, a partir del caso particular de la reforma a la enseñanza del Derecho en la Universidad de los Andes, se puede pensar en una teoría que explica la forma en que la definición de qué es el Derecho, cómo debe enseñarse y qué es 
un buen abogado, pasó de ser un proceso centralizado y regulado por la ley, a ser un proceso disperso en el cual la ley no juega un papel central, sino que los mismos profesionales del Derecho son los que determinan qué es la disciplina y qué es ser un buen abogado.

\section{LA FACULTAD DE DERECHO Y SU ASPIRACIÓN A UNA FORMACIÓN INNOVADORA}

Actualmente la Universidad de los Andes se autodefine como una institución "autónoma, independiente e innovadora" que así mismo busca la "excelencia académica e imparte a sus estudiantes una formación crítica y ética". ${ }^{3}$ Desde su fundación, en 1949, la Universidad de los Andes buscó proponer al país un nuevo modelo educativo universitario que respondiera a las exigencias de la sociedad nacional. Sus fundadores apuntaron desde el comienzo a generar "una revolución pedagógica en la educación superior”. ${ }^{4}$

Esta idea de innovación no fue ajena a los orígenes de la Facultad de Derecho, fundada en 1968. Desde sus inicios la Facultad tuvo el objetivo de "apartarse de la enseñanza magistral y memorística, y de la importancia dada a los fines privados del Derecho de las Facultades de

3 UNIVERSIDAD DE LOS ANDES. Consultado el 19 de noviembre de 2012, en: http://www.uniandes.edu.co/la-universidad/informaciongeneral/mision

4 BELL LEMUS, G., PINZÓN DE LEWIN, P., MORALES REGUEROS, L., ROJAS ROA, D. Historia de la Universidad de los Andes. Bogotá: Uniandes, 2008, p. 66.
Derecho". ${ }^{5}$ De acuerdo con el relato histórico de Álvarez Correa fueron tres los criterios fundamentales que guiaron el desarrollo de la Facultad: i) que además de servir los fines privados del Derecho, esta disciplina debía servir como instrumento de desarrollo de la sociedad; ii) la metodología en la enseñanza del Derecho debía orientarse a la técnica del curso activo; y iii) la formación jurídica debía estar aparejada por un fuerte componente humanista. ${ }^{6}$

Si bien esta ha sido la orientación de la Facultad desde su fundación, la reforma a la enseñanza del Derecho, puesta en práctica en el segundo semestre de 1997 pero proyectada desde el Plan de Desarrollo 1995 - 2000 (en adelante Plan de Desarrollo), durante la decanatura de Alfredo Lewin Figueroa (1994 - 1996), parece ser la cúspide del proyecto inicial. En efecto, hay algo particular en dicha reforma que marca un hito en la historia de la Facultad. Esta particularidad se evidencia en un documento interno de trabajo titulado Antecedentes de la reforma a la enseñanza del Derecho. ${ }^{7}$ En el acápite Recuperar los orígenes, se señala: "La reforma que ahora se propone preserva el espíritu original de la Facultad que en la actualidad tiene mayor vigencia que nunca". ${ }^{8}$ Algo particular hay en esta frase. Pensar en una reforma que preserva un

5 UNIVERSIDAD DE LOS ANDES. Facultad de Derecho. Plan de Desarrollo 1995-2000. Bogotá: Uniandes, 1996, p. 49.

$6 \quad$ Ibíd. P. 49

7 UNIVERSIDAD DE LOS ANDES, Facultad de Derecho. Antecedentes de la reforma a la enseñanza del Derecho. [Documento interno de trabajo]. Archivo personal.

$8 \quad$ Ibíd 
espíritu original parece contradictorio, o al menos indica implícitamente que ese espíritu original se perdió en algún punto del camino.

Esto podría ser corroborado por un diagnóstico preliminar realizado por la profesora Marcela Castro, y contenido en su reflexión sobre la orientación estratégica de la Facultad respecto al Plan de Desarrollo 1995 - 2000. ${ }^{9}$ Uno de sus hallazgos fue que la misión que se había dado la propia Facultad en 1968 parecía no ser acorde con la realidad que esta mostraba en 1995. Para Castro, existía la percepción de que el objetivo de la formación de un abogado diferente, a través de una metodología innovadora, se había quedado corto. No obstante, esto ocurría no solo por la lógica propia de la enseñanza en la Facultad, sino también porque en ese entonces se veía un cambio no solo en el país sino en el mundo. ${ }^{10}$

Las razones externas y el contexto que pudieron haber llevado a esta reforma empezaron a vislumbrarse en los términos en que la Facultad describía su misión en 1995, según los cuales ya se veía inmersa en una realidad histórica concreta:

En el marco de una sociedad en crisis estructural, concebimos el Derecho y su ejercicio como un instrumento al servicio del ser humano, de la democracia, y del desarrollo, orientado por un imperativo moral de justicia que le dé prioridad a la equidad social sobre la utilidad particular y por una cultura ética, determinada

$9 \quad$ Universidad de los Andes. Ob. cit., p. 52.

10 Ibíd. P. 55. por valores de libertad, participación y respeto a la pluralidad. La Facultad tiene como misión, educar y formar estudiantes y profesionales competentes, críticos y comprometidos con su sociedad, con un conocimiento jurídico actualizado, integral y dinámico, fruto de una actividad académica e investigativa autónoma, sistemática e innovadora que les permita desempeñarse idóneamente en las distintas facetas de su profesión, siempre en la búsqueda y realización de un futuro mejor en un mundo solidario. ${ }^{11}$

\section{CONTEXTO DE LA REFORMA DE 1997}

Para la Facultad, el entorno que rodeó la reforma de 1997 estuvo marcado por tres factores determinantes: un nuevo contexto nacional e internacional, el debate sobre el "Nuevo Derecho" y el estado crítico de la enseñanza del Derecho en Colombia. ${ }^{12}$

Para la Facultad, la coyuntura nacional se veía enlazada por los procesos de globalización vigentes en la época. Dentro de los sucesos más relevantes se encontraban los siguientes:

la Constitución de 1991, los anhelos de renovación política, la búsqueda de la democratización de los diferentes espacios de poder a través de la democracia participativa, la proyección de Colombia en el escenario político internacional, los procesos de integración eco-

11 lbíd. P. 35.

12 UNIVERSIDAD DE LOS ANDES, Facultad de Derecho. Antecedentes de la Reforma a la Enseñanza del Derecho. [Documento interno de trabajo]. Archivo personal. 
nómica y de internacionalización, la rápida incorporación de las tecnologías informáticas y la revolución de las telecomunicaciones (...). ${ }^{13}$

Estos cambios en la realidad nacional e internacional llamaban a "aproximaciones creativas" desde diversas disciplinas, incluida por supuesto el Derecho. Así mismo, la Facultad veía a la justicia jugando un papel fundamental en “(...) el sostenimiento de la democracia, los procesos de paz y en el crecimiento económico, la aceptación del pluralismo y la diversidad como esencia de nuestra nacionalidad y base de la convivencia democrática". ${ }^{14}$

La Constitución de 1991 fue otro factor determinante en el contexto que rodeó la reforma. En efecto, para la Facultad, la expedición de la Constitución de 1991 abrió en Colombia el debate sobre el Nuevo Derecho. Bajo esta perspectiva el Derecho "no se concibe como una disciplina autofundada sino interdependiente de otras ciencias sociales, situada en un contexto real y llamada a responder a las necesidades y expectativas de la comunidad". ${ }^{15}$

Para la Facultad, la realidad nacional e internacional así como el debate en torno al Nuevo Derecho estarían evidentemente atados a la educación del abogado en Colombia. Un estudio del Ministerio de Justicia y del Derecho, publicado en 1995, evidenció cómo la enseñanza del De-

13 Ibíd.

14 Ibíd.

15 Ibíd recho no respondía a la nueva coyuntura. ${ }^{16}$ Este estudio, el cual consultó la opinión de estudiantes, docentes, egresados y ciudadanos llegó a la siguiente conclusión frente a la educación de los abogados:

Los entrevistados reconocen la existencia de fallas en la educación del abogado, por lo que no se le están dando herramientas teóricas ni éticas para responder a las necesidades de Colombia hoy. Se hace imperiosa la necesidad de tomar acciones tendientes al mejoramiento de: el currículo, la calidad de los estudiantes y la calidad y condiciones laborales de los docentes. ${ }^{17}$

El diagnóstico al que llegó el citado estudio definió en gran medida los temas centrales de la reforma a la enseñanza del Derecho en la Universidad de los Andes. No obstante, y cómo se desarrollará más adelante, uno de los factores determinantes para la realización de la reforma a la enseñanza fue la autonomía universitaria establecida en la Constitución Política de 1991.

Adicional a este contexto, es importante tener en cuenta el papel que jugó el entonces rector de la Universidad, Rudolf Hommes Trujillo. De acuerdo con Cristina Motta -quien hizo parte del comité que nombró el entonces decano de la Facultad, Manuel José Cepeda (1996-2000), para llevar a cabo la reforma- desde su llegada el rector estuvo interesado en desarrollar ideas novedosas en el tema de la educación, y la carrera de Derecho no era ajena a esos pro-

\footnotetext{
16 MINISTERIO DE JUSTICIA Y DEL DERECHO. El abogado en el tiempo de la gente: Realidad y prospectiva de la enseñanza del Derecho en Colombia. Bogotá: Autor, 1995

17 Ibíd. P. 126
} 
pósitos. Ya desde la decanatura de Eduardo Álvarez Correa $^{18}$ (1977-1982), quien antecedió a Manuel José Cepeda, se empezaron a elaborar documentos relativos a formas alternativas de reformar la educación jurídica que en ese entonces ofrecía la Facultad. Tras realizar viajes a México y Argentina con el fin de explorar temas de enseñanza del Derecho, Cristina Motta compartió puntos de vista con el rector y fueron esas conversaciones las que "sirvieron de impulso para preparar el terreno institucional en el que se apoyaría la reforma". ${ }^{19}$

\section{A. Libertad de cátedra y autonomía universitaria}

Antes que la Constitución de 1991 (artículo 69) consagrara la autonomía universitaria, el Decreto 1221 de 1990 determinó los requisitos mínimos para la creación y funcionamiento de los programas de Derecho. ${ }^{20}$ Este Decreto establecía la necesidad de autorización previa del Instituto Colombiano para el Fomento de la Educación Superior (en adelante ICFES) para que un programa de Derecho pudiera funcionar. Así mismo, una certificación del Departamento Na-

18 Eduardo Álvarez Correa fue una figura clave en la formación del espíritu renovador de la Facultad en ese entonces. Durante su decanatura se prestó especial atención al empleo de una pedagogía acorde con la misión de la Facultad.

MOTTA, Cristina. Comunicación personal, 17 de noviembre de 2012.

20

Si bien para efectos de este ensayo solo se hace referencia al Decreto 1221 de 1990 por ser el que estableció el escenario inmediatamente anterior a la autonomía universitaria consagrada en la Constitución de 1991, es importante señalar que desde 1918 el Estado estaba facultado para exigir títulos de idoneidad para ejercer la profesión de abogado. Ver, SALAMANCA RAMÍREZ, F. Reseña histórica de la regulación de la enseñanza del Derecho. En: GARCÍA VILLEGAS, M. (Eds.). Los abogados en Colombia. Bogotá: Universidad Nacional, Facultad de Derecho, Ciencias Políticas y Sociales, p. 61-89. cional de Planeación que demostrara la concordancia del programa con el Plan Nacional de Desarrollo Económico y Social y las necesidades de la región. En lo que respecta al plan de estudios para la carrera de Derecho, el capítulo IV del Decreto establecía muy estrictamente las materias básicas y obligatorias para todo estudiante. ${ }^{21} \mathrm{En}$ cuanto a la metodología de enseñanza, el artículo 16 instituía que esta debía alternar entre la disertación magistral y "la información general con la participación activa del estudiante en sistemas de aplicación tales como comunidades de trabajo, talleres preseminarios, seminarios, prácticas de distinta índole y consultorio o clínicas jurídicas".

La Constitución Política de 1991 reconoció en su artículo 27 la libertad de cátedra, concepto que la Corte Constitucional ha entendido como la

capacidad de autorregulación filosófica y de autodeterminación administrativa y por ello al amparo del texto constitucional cada institución universitaria ha de contar con sus propias reglas internas (estatutos), y regirse conforme a ellas; designar sus autoridades académicas y administrativas; crear, organizar y desarrollar

21 El artículo 11.a señalaba como materias obligatorias las siguientes: Introducción al Derecho, Teoría Económica, Economía Colombiana, Filosofía del Derecho, Ética Profesional, Teoría Constitucional, Derecho Constitucional Colombiano, Derecho Administrativo General y Especial, Derecho Internacional Público, Hacienda Pública o Finanzas Públicas, Derecho Romano, Derecho Civil parte general y personas, Bienes, Obligaciones, Contratos, Familia, Sucesiones, Derecho Comercial General y Especial, Derecho Penal General y Especial, Derecho Laboral Individual y Colectivo y Derecho de la Seguridad Social, Teoría General del Proceso, Derecho Procesal Civil, Derecho Procesal Penal, Derecho Procesal Laboral, Derecho Procesal Administrativo y Derecho Probatorio. A estas materias teóricas se sumaban las "Metodológicas" y "Prácticas" aunque el Decreto no describía minuciosamente su contenido. 
sus programas académicos, definir, y organizar sus labores formativas, académicas, docentes, científicas y culturales; otorgar los títulos correspondientes, seleccionar a sus profesores, admitir a sus alumnos, adoptar sus correspondientes regímenes y establecer, arbitrar y aplicar sus recursos para el cumplimiento de su misión social y de su función institucional. ${ }^{22}$

De acuerdo con lo anterior, las universidades tienen libertad (al menos formal) para escoger su orientación filosófica, autorregularse y decidir el contenido y metodología a usar en los programas académicos por ellas ofrecidos. ${ }^{23}$

La regulación jurídica de la educación superior fue establecida a partir de la Ley 30 de 1992. Esta ley, tal como su artículo $3^{\circ}$ lo señala, buscaba satisfacer dos objetivos: garantizar la autonomía universitaria y al mismo tiempo velar por la calidad del servicio educativo mediante la inspección y vigilancia por parte del Estado de la educación superior.

La consagración de la autonomía universitaria a nivel constitucional y la lenta reglamentación que se dio a la Ley 30 de 1992 permitieron que muchas instituciones de educación superior abrieran programas de Derecho de baja calidad académica. ${ }^{24}$ En respuesta a esto se expidieron varios decretos tendientes a establecer criterios

22 COLOMBIA, Corte Constitucional, sentencia T- 492 de 1992, M. P.: José Gregorio Hernández Galindo.

23 Para una lectura crítica que considera la consagración de la autonomía universitaria a nivel constitucional y el desarrollo jurisprudencial dado por la Corte como una simple eficacia simbólica, ver, BOTERO BERNAL, A. Autonomía universitaria. Desarrollo e impacto del concepto en Colombia. Medellín: Universidad de Antioquia, 2005, p. 112.

SALAMANCA RAMÍREZ. Ob. cit., p. 61. y estándares mínimos de calidad de los diferentes programas. ${ }^{25}$ No obstante, estos criterios, contrarios a los del Decreto 1221 de 1990, no establecían el contenido ni la metodología que debía seguir la carrera de Derecho, pues consistían en determinar la información del programa ${ }^{26}$ que las instituciones de educación superior debían presentar, tal como el nombre de este, título que otorgaba, plan de estudios, perfil profesional, estrategia metodológica, jornada, recursos, número de docentes, etc., a fin de que el Ministerio de Educación Nacional hiciera recomendaciones para que los programas se desarrollaran de acuerdo con los objetivos de la educación superior. Esto permitió que la reforma a la enseñanza del Derecho en la Universidad de los Andes se llevara a cabo sin estar limitada por una normatividad particular que le indicará qué enseñar y cómo hacerlo. Alfredo Fuentes Hernández señala que si bien el Decreto 1221 de 1990 no fue derogado explícitamente, las Facultades consideraron que había perdido vigencia, pues en la práctica los programas de Derecho se apartaron de sus disposiciones al encontrarlas contrarias al principio de autonomía universitaria. ${ }^{27}$

25 Por ejemplo: decretos 1403 de 1993, 837 y 2790 de 1994, 1225 de 1996, 807 de 2000, 2802 de 2001 y 2566 de 2003.

26 Artículo 1, Decreto 1403 de 1993

27 FUENTES HERNÁNDEZ, A. Educación legal y educación superior en Colombia: desarrollos institucionales y legales 1990-2002. En: Abogacía y Educación Legal. Disponible en: http://sistemasjudiciales.org/ content/jud/archivos/notaarchivo/434.pdf. Consultado el 19 de noviembre de 2012. Alfredo Fuentes fue decano de la Facultad de Derecho de la Universidad de los Andes desde el año 2000 hasta el año 2005. 


\section{LA REFORMA AL CURRÍCULO \\ EN 1997}

La reforma al currículo en 1997 atendió en gran medida al diagnóstico contenido en el estudio del Ministerio del Interior y de Justicia de $1995 .{ }^{28}$ En sus recomendaciones frente al tema particular del currículo el estudio señalaba:

En esta área nuestra recomendación sería que el currículo básico fuera el mínimo posible. Debería limitarse a la teoría constitucional y el constitucional colombiano, el Derecho privado, la teoría de las obligaciones, la teoría del proceso, el Derecho administrativo, penal general y filosofía del Derecho y algunas materias interdisciplinarias como economía, sociología, metodología, lógica y matemáticas. (...) Lo bá- sico parece ser construir un currículo donde el estudiante aprenda a aprender, identificando las destrezas y habilidades que debe desarrollar un abogado para tener el criterio jurídico, o dicho de otras palabras para pensar como abogado. ${ }^{29}$

Adicionalmente a esta recomendación, la reforma a la enseñanza del Derecho encontró diez objetivos fundamentales a los cuales debía responder, los que, a su vez, contrastaban una situación actual con una propuesta de reforma que contemplaba una serie de mecanismos particulares que permitirían alcanzarlos. Si bien no todos fueron tratados a través de la reforma del currículo, varios de ellos sí lo fueron. Los diez objetivos, con sus propuestas y mecanismos, eran los siguientes: ${ }^{30}$ Saarbrücken: VDM Verlag Dr. Müller, 2008, p. 94.
MINISTERIO DE JUSTICIA Y DEL DERECHO. Ob. cit., p. 132.

Información extraída del documento interno de trabajo "Antecedentes de la reforma a la enseñanza del Derecho" en manos del autor. 


\begin{tabular}{|c|c|c|c|}
\hline OBJETIVO & SITUACIÓN ACTUAL & PROPUESTA & MECANISMOS \\
\hline $\begin{array}{l}\text { Contextualización } \\
\text { del Derecho }\end{array}$ & $\begin{array}{l}\text { Separación entre } \\
\text { realidad y Derecho }\end{array}$ & $\begin{array}{l}\text { Interdisciplinariedad } \\
\text { básica y sensibilidad por } \\
\text { la relación Derecho y } \\
\text { realidad }\end{array}$ & $\begin{array}{l}\text { Ciclo de contextualización ( } 35 \text { créditos); ele- } \\
\text { mentos de realidad en todos los cursos; cursos } \\
\text { de Argumentación I y II; Primer Examen de Fa- } \\
\text { cultad. Ensayo Derecho-realidad. }\end{array}$ \\
\hline $\begin{array}{l}\text { Integración del } \\
\text { Derecho }\end{array}$ & $\begin{array}{l}\text { Fragmentación de } \\
\text { las materias }\end{array}$ & Materias integradoras & $\begin{array}{l}\text { Ciclo de formación básica en Derecho ( } 84 \text { cré- } \\
\text { ditos); cursos integradores: disminución de } \\
\text { materias y créditos; segundo examen de Facul- } \\
\text { tad: evaluación de capacidad de integración y } \\
\text { estructuración, además de contenidos básicos. }\end{array}$ \\
\hline $\begin{array}{l}\text { Reequilibrio de } \\
\text { información- } \\
\text { formación }\end{array}$ & $\begin{array}{l}\text { Frustración de pre- } \\
\text { tensiones enciclo- } \\
\text { pédicas }\end{array}$ & $\begin{array}{l}\text { Revalorizar la formación } \\
\text { del jurista }\end{array}$ & $\begin{array}{l}\text { Integración y estructuración de materias; po- } \\
\text { lítica metodológica de la Facultad: énfasis en } \\
\text { metodologías activas estructuradas; examen } \\
\text { intermedio de Facultad; ciclo de concentra- } \\
\text { ción; disminución semestral de carga acadé- } \\
\text { mica. }\end{array}$ \\
\hline $\begin{array}{l}\text { Formación de } \\
\text { un abogado ar- } \\
\text { gumentador y } \\
\text { analítico }\end{array}$ & $\begin{array}{l}\text { Predominio de la } \\
\text { memorización }\end{array}$ & $\begin{array}{l}\text { Desarrollo de destrezas } \\
\text { argumentativas y analí- } \\
\text { ticas }\end{array}$ & $\begin{array}{l}\text { Curso transversal de argumentación; metodo- } \\
\text { logías activas estructuradas; política metodo- } \\
\text { lógica y de evaluaciones de la Facultad, política } \\
\text { de participación en competencias internacio- } \\
\text { nales. }\end{array}$ \\
\hline $\begin{array}{l}\text { Desarrollo de } \\
\text { capacidades para } \\
\text { la resolución de } \\
\text { problemas }\end{array}$ & $\begin{array}{l}\text { Abogado conocedor } \\
\text { de la ley }\end{array}$ & $\begin{array}{l}\text { Abogado como agente } \\
\text { en la resolución jurídica } \\
\text { de problemas }\end{array}$ & $\begin{array}{l}\text { Contextualización general y al interior de los } \\
\text { cursos; Metodologías activas estructuradas } \\
\text { (aprendizaje basado en problemas); Curso } \\
\text { transversal de argumentación - juez, legisla- } \\
\text { dor, abogado y fiscal; creatividad. }\end{array}$ \\
\hline $\begin{array}{l}\text { Desarrollo de } \\
\text { la capacidad de } \\
\text { autoestudio en el } \\
\text { estudiante }\end{array}$ & $\begin{array}{l}\text { Estudiante receptor } \\
\text { de verdades }\end{array}$ & Aprender a aprender & $\begin{array}{l}\text { Énfasis en metodología de resolución de pro- } \\
\text { blemas; Inducción metodológica para profeso- } \\
\text { res; Evaluación de capacidad de autoestudio } \\
\text { del estudiante. }\end{array}$ \\
\hline $\begin{array}{l}\text { Evaluación del } \\
\text { estudiante a lo } \\
\text { largo de su for- } \\
\text { mación }\end{array}$ & $\begin{array}{l}\text { Exámenes prepara- } \\
\text { torios compartimen- } \\
\text { tados }\end{array}$ & $\begin{array}{l}\text { Tres series de exáme- } \\
\text { nes de Facultad al final } \\
\text { de cada ciclo }\end{array}$ & $\begin{array}{l}\text { 1a serie: ensayo Derecho-realidad (final ciclo } \\
\text { de contextualización). } \\
\text { 2a serie: examen en Derecho público y Dere- } \\
\text { cho privado (final ciclo de formación básica en } \\
\text { Derecho). } \\
\text { 3a serie: examen en área de concentración y } \\
\text { en materia no cursada. } \\
\text { Política general de evaluaciones de la Facultad. }\end{array}$ \\
\hline
\end{tabular}




\begin{tabular}{|l|l|l|l|}
\hline $\begin{array}{l}\text { Vinculación del } \\
\text { pregrado a la } \\
\text { investigación }\end{array}$ & $\begin{array}{l}\text { Investigación solo } \\
\text { es un requisito de } \\
\text { grado }\end{array}$ & $\begin{array}{l}\text { Vincular el pregrado y } \\
\text { la investigación }\end{array}$ & $\begin{array}{l}\text { Mayor espacio para investigación; tres semes- } \\
\text { tres para investigación dirigida; metodologías } \\
\text { activas que promueven investigación; curso } \\
\text { transversal de argumentación. }\end{array}$ \\
\hline $\begin{array}{l}\text { Promoción y } \\
\text { respuesta a las } \\
\text { vocaciones e } \\
\text { intereses de los } \\
\text { estudiantes }\end{array}$ & $\begin{array}{l}\text { Formación unifor- } \\
\text { madora }\end{array}$ & $\begin{array}{l}\text { Formación promotora } \\
\text { de vocaciones que ofre- } \\
\text { ce opciones }\end{array}$ & $\begin{array}{l}\text { Tres áreas de concentración o navegación es- } \\
\text { pecial; } 30 \text { créditos para profundizar en área } \\
\text { elegida; evaluar profundidad de conocimiento } \\
\text { (tercera serie de exámenes); 18 créditos para } \\
\text { optativas en cualquier Facultad; 18 créditos } \\
\text { dentro de la bolsa de contextualización. }\end{array}$ \\
\hline $\begin{array}{l}\text { Fortalecimiento } \\
\text { de la relación en- } \\
\text { tre los estudian- } \\
\text { tes y la Facultad }\end{array}$ & $\begin{array}{l}\text { Contactos esporá- } \\
\text { dicos }\end{array}$ & $\begin{array}{l}\text { Consejería estudiantil } \\
\text { organizada }\end{array}$ & $\begin{array}{l}\text { Sistema de consejería estudiantil organizado; } \\
\text { consejería elemento de la carga profesoral; } \\
\text { comunicación y seguimiento constante de los } \\
\text { estudiantes; esquema de participación estu- } \\
\text { diantil; orientación profesional para escoger } \\
\text { concentración. }\end{array}$ \\
\hline
\end{tabular}

Alcanzar estos objetivos implicaba cambios importantes dentro del currículo, en opinión de la Facultad y del entonces decano Manuel José Cepeda. ${ }^{31}$ Así, mientras que en el currículo anterior a la reforma la carrera constaba de 212 créditos, después de la reforma se contaban 177; en tanto que en el esquema anterior se realizaban cinco exámenes preparatorios, con la reforma se realizaban tres exámenes, cada uno en distintos momentos de la carrera. Un cambio fundamental y que aún perdura es la organización del currículo en ciclos. En el primer ciclo se buscaría contextualizar el Derecho como una disciplina conectada y afectada por otras ciencias y con una incidencia clara en la realidad social. El segundo ciclo comprendería la formación básica en Derecho público y privado; este fue

31 La reforma a la enseñanza del Derecho pudo encontrar inspiración en la visión que el entonces decano Manuel José Cepeda tenía sobre la nueva Constitución de 1991 y su interpretación, Ver, CEPEDA ESPINOSA, M. Los Derechos y la Interpretación de la Nueva Constitución. En: Revista de Derecho Público, 1991, n. 1. el que más cambió con la reforma, por ejemplo, los cursos Derecho Constitucional General y Derecho Constitucional Colombiano I y II pasaron a ser condensados en el curso Derecho Constitucional. Casos similares se presentaron en las materias de Derecho Administrativo, Derecho Penal y Derecho Procesal, el cual pasó de tener ocho cursos a solo tres. De acuerdo con Montoya, los cambios realizados a estos cursos (condensación y eliminación de algunos) hacían evidente el hecho de que la información transmitida en ellos era menor en comparación con otros currículos contemporáneos. Esta decisión de parte de la Universidad implicó varias críticas que en ese entonces rodearon al proceso. ${ }^{32} \mathrm{El}$ tercer y último ciclo se destinó a la concentración que el estudiante escogiera entre Derecho público, privado o teoría jurídica.

32 Ver, MONTOYA, J. Ob. cit., p. 97. 
Vista desde una perspectiva más general, la reforma perseguía apartarse de una visión tradicional que buscaba un conocimiento enciclopédico del Derecho, y favorecer, en cambio, "la aprehensión y entendimiento contextualizado de[l] mismo, su integración con los temas conexos, y el desarrollo de habilidades críticas, analíticas y de solución de problemas". ${ }^{33}$ Igualmente, el currículo y la metodología propuesta en la reforma buscaban priorizar una educación general, por encima de un entrenamiento técnico para lo que sería la vida laboral del futuro abogado Uniandino. Este es un punto importante que hay que resaltar, pues al dar una visión general la reforma se proponía abrir también los campos de realización profesional del futuro abogado. Bajo esta perspectiva, el rol tradicional del abogado no sería el único camino disponible para el estudiante de Derecho: su conocimiento podría desarrollarse y aplicarse en otras múltiples formas y áreas. Como señala Montoya: “La educación jurídica general pretende ser una educación multipropósito, que no solo se dirija a una cierta práctica del Derecho sino a cualquier otro tipo de práctica profesional". ${ }^{34}$ Así mismo, la decisión de privilegiar la educación general por encima del contenido puntual y específico pretendía también darle una vigencia casi que infinita a la formación universitaria, pues la aprehensión de principios generales del Derecho y de métodos analíticos y metodológicos para resolver problemas permitiría al aboga-

33 MONTOYA, J. (2008). La reforma a la enseñanza del Derecho en la Universidad de los Andes. En: Cuadernos Unimetanos, 2008, nº. 15, p. 74. do adaptarse a los cambios que sufre el ordenamiento jurídico constantemente:

Una educación general, se entiende que prepara mejor a los futuros profesionales para enfrentar el cambio, de lo que puede hacerlo la enseñanza de las normas en vigor. Un supuesto clave es que la educación general prepara mejor para la práctica, cuando dicha práctica se entiende en términos amplios. ${ }^{35}$

En síntesis, el currículo propuesto en la reforma evidenciaba el deseo de la Facultad de ofrecer una educación legal de carácter general, que permitiera al abogado Uniandino desempeñarse exitosamente en distintos campos profesionales, sin limitarlo a la práctica profesional y tradicional del Derecho. ${ }^{36}$

La reforma a la enseñanza del Derecho fue presentada el 15 de mayo de 1997 por el entonces decano Manuel José Cepeda (1996-2000), ante el Consejo Académico de la Universidad. ${ }^{37}$ Con el fin de estudiar esta propuesta se creó una comisión que estaría a cargo de presentar su recomendación al Consejo Académico. ${ }^{38}$ Posteriormente, y tras el informe de la comisión, el Consejo Académico aprobó la reforma ${ }^{39}$ que fue

\footnotetext{
35 Ídem.

36 Ídem.

37 UNIVERSIDAD DE LOS ANDES. CONSEJO ACADÉMICO DE LA UNIVERSIDAD. Acta No. 11 de 15 de mayo de 1997.

38 Esta comisión estuvo presidida por el entonces vicerrector Ulpiano Ayala y conformada por Claudia Rebolledo, Manuel José Cepeda, Cristina Motta, Karen Rogers, Francisco Leal y Jorge Hernán Cárdenas.

39 UNIVERSIDAD DE LOS ANDES. CONSEJO ACADÉMICO DE LA UNIVERSIDAD. Acta No. 13 de 29 de mayo de 1997.
} 
ratificada posteriormente por el Comité Ejecutivo de la Universidad, el 30 de julio de $1997 .{ }^{40}$

\section{INTERMEZZO: 1997 - 2005}

Desde su puesta en marcha, en el segundo semestre de 1997, la reforma a la enseñanza ya tenía una fuerte oposición al interior de la Facultad. Por lo mismo, para Juny Montoya, ${ }^{41}$ hablar de una "contrarreforma" en sentido estricto para nombrar los cambios al currículo en el año 2005 no sería del todo correcto. ${ }^{42}$ La idea de reformar la enseñanza del Derecho surgió de un pequeño grupo de profesores de tiempo completo, bajo la dirección del decano de ese entonces. Si bien la propuesta de reforma se discutió con la comunidad de la Facultad (alumnos, exalumnos, exdecanos y profesores de cátedra) y se hicieron algunos ajustes a la propuesta inicial, no hubo consenso total alrededor de ella. De acuerdo con la investigación de Montoya, los profesores de cátedra fueron la comunidad que presentó mayor resistencia y escepticismo debido a que asumían que esta podría implicar que algunos de ellos dejaran de enseñar en la Facultad $^{43}$; adicionalmente, carecían de tiempo para planificar y entrenarse en la nueva metodología y estructura y, por otra parte, experimentaban

40 UNIVERSIDAD DE LOS ANDES. CONSEJO EJECUTIVO DE LA UNIVERSIDAD. Acta No. 15 de 30 de julio de 1997.

Juny Montoya, como miembro del Comité de diseño de la reforma, participó desde el comienzo en su preparación e implementación.

42 Entrevista con Juny Montoya, Ex directora del Centro de Investigación y Formación en Educación de la Universidad de los Andes y actual Directora del Centro de Ética Aplicada de la misma Universidad.

43 MONTOYA, J. Ob. cit., p. 99. un sentimiento de nostalgia pues para la nueva Facultad, el prestigio profesional de los profesores de cátedra dejaba de ser importante. ${ }^{44}$

Los beneficios de la reforma a la enseñanza también se ponían en entredicho, en ese entonces, por otros dos factores identificados en la investigación de Otero y Jiménez. El primero, la idea de que la metodología de enseñanza basada en el aprendizaje a través de solución de problemas formaría abogados con capacidades argumentativas pero sin herramientas para su desarrollo profesional. El segundo, el crecimiento de la población estudiantil cruzado con una política institucional de la Universidad referente al tamaño de los cursos, lo cual hacía difícil el desarrollo del aprendizaje a través de resolución de problemas que, en teoría, no se debería aplicar a cursos de más de 15 estudiantes. ${ }^{45}$

Como consecuencia, el currículo que emergió de la reforma de 1997 vio unas primeras alteraciones puntuales durante la decanatura de Alfredo Fuentes (2000-2004): el traslado de las materias de Hermenéutica, Derecho de la Empresa y Qué es lo público, del ciclo de concentración al ciclo básico, cambio que implicó convertir Derecho de la Empresa en Derecho Comercial y Qué es lo público en Contratos estatales. ${ }^{46}$

\footnotetext{
44 Ibíd., p. 100.

45 OTERO CLEVES, A., JIMÉNEZ ÁNGEL, A. Cuarenta años innovando el Derecho: una mirada a la Facultad de Derecho de la Universidad de los Andes (1968-2008). Bogotá: Universidad de los Andes, 2010, pp. 80-81.
}

46 UNIVERSIDAD DE LOS ANDES. CONSEJO ACADÉMICO DE LAFACULTAD DE DERECHO. Acta No. 14 de agosto 25 de 2004. 


\section{LA REFORMA DE 2005}

Tras los cambios realizados en el año 2004, el currículo tuvo modificaciones importantes en su ciclo de formación básica y de concentración, en la reforma aprobada por el Consejo Académico de la Universidad el 26 de mayo de 2005, ${ }^{47}$ bajo la decanatura de Eduardo Cifuentes (20052011), cambio que consistió puntualmente en lo siguiente:

1. Inclusión de tres materias nuevas (Derecho Internacional Privado, Derecho Penal Especial y Derecho Procesal Laboral) en el Consultorio Jurídico.

2. Traslado del Ciclo III (concentración) al Ciclo II (formación básica) de las siguientes materias: Sociedades, Títulos Valores, Acciones Públicas (Derecho Contencioso Administrativo) y Procesos Ejecutivos y Declarativos.

3. Modificación del contenido de algunas materias.

a. El curso Ensayo y Realidad Social (Argumentación II) de segundo semestre. Los objetivos de este curso y su contenido específico serán retomados en el curso de Sociología Jurídica.

b. El curso de Hacienda Pública será facultativo del área de Público (...)

c. El curso de Mediación, Negociación y Conciliación (Argumentación VII) se elimina y su UNIVERSIDAD. Acta No. 222 de 26 de mayo de 2005. contenido sustancial se incorpora en los cursos de Derecho Procesal Civil.

4. Modificación de los cursos obligatorios de las áreas de Concentración de Público y Privado en el Ciclo III. Se busca integrar el Ciclo III con seis materias facultativas.

La realización de estos cambios generó, al menos en los estudiantes, la sensación de que el currículo volvía al concepto tradicional de la enseñanza del Derecho. En la misma reunión donde el Consejo Académico aprobó la reforma, Laura Barragán, representante estudiantil, formuló un comentario en representación de la Mesa de Trabajo del Consejo Estudiantil Uniandino, el cual quedó consignado en el Acta de la siguiente forma: "Las modificaciones propuestas podrían dar a entender que se desvirtúa el perfil de abogado que inspira al programa, regresando al abogado tradicional." En respuesta a este comentario, el decano Cifuentes aclaró que no se trataba de un “(...) cambio estructural al programa ni a su metodología, sino que los ajustes respond[ían] a la necesidad de brindar a los estudiantes las herramientas jurídicas básicas [para] ejercer la profesión". ${ }^{48}$ Para él, hoy en día, la reforma de 2005 fue una gran conquista en la que participaron todos los profesores y estudiantes; su fin no fue otro que fortalecer el ciclo de formación básico llenando algunos vacíos detectados por algunos profesores pero sin buscar tampoco un conocimiento enciclopedista o exhaustivo del Derecho, y si bien fue difícil realizarla pues para algunos profesores que hicieron parte activa del grupo que promovió la reforma

48 Ibíd 
de 1997 hablar de cambios en la Facultad era un tabú, al final esta era necesaria y los mismos alumnos la reclamaban. ${ }^{49}$

\section{EL CONTEXTO DE LA REFORMA DE 2005}

Más allá de los cambios puntuales al currículo, lo que interesa para los propósitos de este artículo es encontrar las razones de ellos y el contexto que los rodeó. El documento de trabajo interno Propuesta de ajustes al Plan de Estudios de la Facultad de Derecho, ${ }^{50}$ de fecha 12 de abril de 2005, aprobado por el Consejo de la Facultad de Derecho el 15 de abril de 2005, ${ }^{51}$ señala en el acápite Problemas actuales, lo siguiente:

El ajuste curricular mencionado en el año de 2004, es insuficiente para fortalecer el Ciclo II, especialmente para la formación jurídica del abogado(a) uniandino(a). Así lo demuestran estudios específicos de evaluación del pensum que han realizado las áreas de Derecho Procesal, Derecho Penal, Derecho Privado y Derecho Laboral, entre otros.

El mismo documento indica que de acuerdo con el informe "Documento de planteamientos estratégicos de las áreas, programas, centros y publicaciones de la Facultad", presentado al de-

49 Entrevista con Eduardo Cifuentes, exdecano de la Facultad de Derecho de la Universidad de los Andes (2005-2011). Bogotá, noviembre 15 de 2012

50 UNIVERSIDAD DE LOS ANDES, FACULTAD DE DERECHO. Propuesta de ajustes al Plan de Estudios de la Facultad de Derecho. [Documento interno de trabajo]. Archivo personal.

51 UNIVERSIDAD DE LOS ANDES. CONSEJO ACADÉMICO FACULTAD DE DERECHO. Acta 5 del 15 de abril de 2005. cano en marzo de 2005, se llegó a la conclusión que "existe un conjunto de 10 cursos o materias de gran importancia en la formación jurídica del abogado, y que no aparecen en el pensum actual del programa de Derecho".52

Además del diagnóstico realizado por la Facultad y del contenido de los documentos mencionadas previamente, de acuerdo con las discusiones consignadas en las actas del Consejo Académico el decano Cifuentes tuvo como razones principales para la modificación del currículo los deficientes resultados en los exámenes ECAES, y los comentarios realizados por los pares evaluadores en el proceso de acreditación finalizado exitosamente en 2003.

\section{A. Los deficientes resultados en el ECAES}

En la sesión extraordinaria del Consejo Académico de la Facultad, Ilevada a cabo el 7 de abril de 2005, se trató el tema de los resultados deficientes de la Facultad de Derecho en el examen ECAES. Según el acta 218 de 2005, el decano manifestó que si bien hay varias razones que pueden explicar los resultados

(...) cabe destacar la reforma curricular, a partir de la cual se elaboró el plan de estudios actual de la Facultad, que estuvo centrada en formar

52 Las diez materias mencionadas son: Personas, Derecho Internacional Privado, Sociedades Comerciales, Títulos Valores, Derecho Penal Especial, Derecho Procesal Constitucional, Derecho Contencioso Administrativo, Derecho Procesal Laboral, Derecho Procesal Civil y Derecho Procesal Penal. El mismo documento señala que en algunos casos, como por ejemplo en Derecho Procesal Civil, el contenido está fragmentado y disperso en otros cursos del Ciclo II, como son "Procedimientos" y "Pruebas". Otros de estos cursos son dictados dentro del ciclo de concentración, ya sea en Derecho público y privado. En otros casos, como en Derecho Penal Especial, el mismo documento reconoce que dicho curso no se dicta en la Facultad. 
abogados que manejaran estrategias argumentativas, fortaleciendo el análisis y la teoría jurídica. Esto trajo como consecuencia que materias básicas para la formación de abogados, como civil, penal, laboral y procesal, se hayan dejado en un segundo lugar. Es así como el problema de fondo está en el currículo y es preciso modificarlo parcialmente, de tal forma que unos contenidos mínimos relacionados con el ejercicio de la profesión vuelvan a ser parte del programa ofrecido..$^{53}$

Si bien el acta no indica los resultados de qué año fueron los que se consideraron deficientes, podría presumirse que correspondieron a los años 2003 y 2004. En el 2002, primer año de realización de los ECAES, la Facultad obtuvo el segundo lugar y en razón a esto el rector de la Universidad felicitó al decano Alfredo Fuentes por los resultados obtenidos. ${ }^{54}$ En el año 2003 la Universidad logró el $8^{\circ}$ puesto entre 117 programas, y en el 2004 el $9^{\circ}$ puesto entre el mismo número de programas. A partir de la expedición de la Ley 1324 de 2009 la presentación del ECAES se convirtió en un requisito de obligatorio cumplimiento para obtener el título profesional.

\section{EI ECAES}

El Decreto 1373 de 2002 reglamenta los ECAES del programa de Derecho. El artículo primero los define como

53 UNIVERSIDAD DE LOS ANDES. CONSEJO ACADÉMICO UNIVERSIDAD DE LOS ANDES. Acta No. 218 de 7 de abril de 2005.

54

UNIVERSIDAD DE LOS ANDES. CONSEJO ACADÉMICO UNIVERSIDAD DE LOS ANDES. Acta No. 147 de 8 de agosto de 2002.
Una modalidad de Examen de Estado para la evaluación externa de los estudiantes de último semestre para los programas que se ofrezcan anual o semestralmente, y forman parte, con otros procesos y acciones, de un conjunto de instrumentos que el Gobierno Nacional dispone para evaluar y mejorar la calidad de la educación.

De acuerdo con el mismo decreto sus objetivos son, entre otros,

a) Comprobar niveles mínimos de conocimientos de los estudiantes de último semestre de pregrado de Derecho; b) Servir de instrumento para la homologación y convalidación de títulos de estudios de Educación Superior realizados en el exterior.

El ECAES examina el conocimiento de las siguientes áreas como mínimo: Derecho Civil y de Familia, Derecho Constitucional, Derecho Administrativo, Derecho Penal, Derecho Laboral, Derecho Comercial y Derecho Internacional; y un área humanística que incluye Teoría General del Derecho (filosofía del Derecho, sociología jurídica, historia del Derecho e historia de las ideas políticas). ${ }^{55}$ Estas áreas examinadas por el ECAES coinciden con los requisitos mínimos que debe tener todo programa de Derecho, tal como lo establece el Decreto 2802 de 2001 y la Resolución 2768 de 2003 del Ministerio de Educación Nacional. ${ }^{56}$

Artículo 3, Decreto 1373 de 2002.

5

Es importante mencionar que el mismo Decreto 2802, si bien establece estas áreas como contenido mínimo que debe tener un programa de Derecho, también reconoce que "cada institución organizará dentro de su currículo estas áreas y sus componentes, así como otras que considere pertinentes, en correspondencia con su misión y proyecto institucional." 


\section{Los resultados de los ECAES 2003 y 2004 vistos desde la Facultad}

Los resultados de los exámenes ECAES 2002, 2003 y 2004, y sus análisis correspondientes, así como el plan estratégico de preparación para los estudiantes que presentarían el examen en el 2005, están contenidos en un documento interno de trabajo de la Facultad, fechado el 9 de junio de $2005 .{ }^{57}$ Como se señaló anteriormente, en el 2002 la Facultad ocupó el segundo lugar en tales exámenes. Para los años 2003 y 2004 ocupó el 8 y 9 lugar respectivamente, entre 117 programas.

En el documento interno de trabajo se encuentra que tras analizar los resultados de los tres exámenes hasta ese momento presentados, la Facultad realizó una autoevaluación buscando explicaciones a los pobres desempeños obtenidos en 2003 y 2004, con las siguientes razones:

1. Los estudiantes no están entrenados para la presentación de los exámenes ECAES.

2. Los resultados de los estudiantes en las áreas de Derecho Laboral, Derecho Civil y de Familia, Derecho Penal y Responsabilidad profesional los ubican entre el $10^{\circ}$ al $20^{\circ}$ puesto, y con un puntaje por debajo del promedio en relación con otros programas de Derecho.

3. La falta de participación de los profesores de la Universidad en la preparación del examen ECAES 2004.

4. Faltan cursos de formación jurídica básica, a marzo de 2005.

57 Consultado en el archivo personal del autor.
A partir de estas conclusiones se establecieron, según el documento, varias acciones tendientes a mejorar los resultados en el ECAES 2005. Dentro de estas se encuentran exámenes piloto, inclusión de nuevas asignaturas en el currículo y revisión de contenidos de algunas asignaturas, entre otras. De esta forma, el Plan Estratégico se fijó dos objetivos principales:

1. Preparar a los estudiantes para el examen ECAES 2005, especialmente en el desarrollo de habilidades para contestar preguntas y en los contenidos mínimos de cada una de las materias objeto de evaluación.

2. Evaluar en forma permanente la calidad del currículo a partir de los resultados del ECAES.

\section{El proceso de acreditación en 2003}

Además de los deficientes resultados en los exámenes ECAES, la otra razón expuesta por el decano Cifuentes al momento de explicar los cambios al currículo fueron los comentarios de los pares evaluadores en el proceso de acreditación emprendido por la Facultad en el año 2001 y concluido en el 2003 cuando se otorgó la acreditación al programa de pregrado por ocho años. ${ }^{58}$

El hecho que el proceso de acreditación haya sido otra de las razones para la reforma al currículo es ratificado en el documento interno de trabajo "Evaluación del Plan de Estudios del Programa de Derecho y propuesta de ajustes

58 El programa de Derecho fue reacreditado en 2011 por un término de diez años. 
para el 2005-II", el cual en el acápite destinado a explicar las ventajas de la propuesta de reforma señala:

(...) con este ajuste curricular se cumple la exigencia de los pares evaluadores del Consejo Nacional de Acreditación, que recomiendan a la Facultad de Derecho “(...) 1) Realizar algunos ajustes de materias en el contenido del ciclo de formación básica y de concentración (...)". 59

Frente a esta última recomendación de los pares evaluadores no hay claridad, pues el documento cita un informe presentado por los miembros del Consejo Nacional de Acreditación a la Ministra de Educación con fecha 25 de agosto de 2003. Sin embargo, en el informe realizado por los pares evaluadores y remitido al rector de la Universidad, no existe ninguna recomendación de este tipo. La única sugerencia referente al currículo que aparece es

Continuar con la discusión sobre el contenido de los diferentes ciclos que componen el plan de estudios y en especial los de formación jurídica básica y de concentración con miras a la elaboración de criterios académicos más claros y coherentes que permitan llegar a mayores niveles de consenso. ${ }^{60}$

Es importante señalar que el informe que el Consejo Nacional de Acreditación remitió a la Ministra(o) no es el mismo documento que los

59 Este documento fue aprobado por el Consejo de la Facultad de Derecho en el Acta 05 de 2005 y en forma posterior por el Comité Ejecutivo mediante acta 185 de 2005. Consultado en el archivo personal del autor.

60 CONSEJO NACIONAL DE ACREDITACIÓN. Informe de evaluación externa con fines de acreditación, programa de Derecho, Universidad de los Andes, julio 17 de 2003. pares académicos enviaron a la Universidad y en el cual hacen la recomendación antes indicada. Esto lleva a pensar en un posible error en la redacción del documento interno de trabajo de la Facultad, pues es distinto que el Consejo Nacional de Acreditación dé ciertas recomendaciones a que los pares académicos lo hagan. Es claro que en el documento de los pares académicos no existe la recomendación específica de realizar ajustes a las asignaturas que comprenden el ciclo de formación básica. No obstante, para efectos del argumento de este artículo es irrelevante si esa recomendación puntual de modificar el currículo existió o no, o de qué órgano o grupo provino. Lo importante es que la Facultad la entendió como tal y la usó como una razón para justificar la reforma al currículo. Este punto será desarrollado en la séptima parte.

\section{El Sistema Nacional de Acreditación}

La Ley 30 de 1992 creó, mediante su artículo 53, el Sistema Nacional de Acreditación. Este opera como medio para valorar la calidad de los programas de educación superior; así mismo, busca reconocer públicamente altos estándares de calidad con el fin de "preservar derechos legítimos que en esta materia tienen los usuarios del sistema de educación superior y la sociedad global". ${ }^{61}$

El proceso de acreditación no es obligatorio para los programas de pregrado y la decisión

61 SISTEMA NACIONAL DE ACREDITACIÓN, CONSEJO NACIONAL DE ACREDITACIÓN. Lineamientos para la Acreditación de Programas. P. 7. Disponible en: http://cms-static.colombiaaprende.edu.co/cache/binaries/articles-186359_lineamientos_2.pdf?binary_rand=6205. Consultado el 19 de noviembre de 2012. 
sobre iniciarlo o no es completamente autónoma. Está reglamentado por el Decreto 2904 de 1994 y contempla: una autoevaluación por parte de la Facultad (incluyendo en ella personal administrativo, planta profesoral y estudiantes), una evaluación practicada por pares académicos y una evaluación realizada por el Consejo Nacional de Acreditación, quien envía una recomendación al Ministerio de Educación Nacional para que este determine si otorga o no la acreditación mediante un acto administrativo.

Para la Facultad de Derecho el proceso de acreditación realizado en el 2003 y la reciente reacreditación (2012) ${ }^{62}$ son muy importantes. De acuerdo con Carolina Moreno ${ }^{63}$ y Nelson Remolina ${ }^{64}$ esto se explica por tres razones particulares: la primera, porque la Universidad se encuentra actualmente en un proceso de acreditación internacional frente al cual la acreditación nacional representa un importante logro; la segunda, y más fundamental, es que la acreditación, sea nacional o internacional, significa un reconocimiento y prestigio para el programa lo cual es importante para el posicionamiento de la Universidad como una entidad comprometida con la excelencia; y la tercera tiene que ver con el hecho de que el proceso de acreditación

62 La acreditación del programa de pregrado en Derecho fue otorgada por el Ministerio de Educación a través de la Resolución 2110 del 9 de septiembre de 2003 y la reacreditación mediante la Resolución 3982 del 28 de abril de 2012.

63 Entrevista con Carolina Moreno, líder del comité de la Facultad de Derecho de la Universidad de los Andes para el proceso de reacreditación del año 2011, realizada en Bogotá el 9 de noviembre de 2012.

64 Entrevista con Nelson Remolina, coordinador del programa de pregrado en Derecho en el año 2003, realizada en Bogotá el 15 de noviembre de 2012. conlleva la autoevaluación y reflexión interna de la Facultad, es decir, que la acreditación si bien tiene un valor en sí misma, comporta la posibilidad de hacer un alto en el camino para autoexaminarse.

\section{Los comentarios de los pares académi- cos en el proceso de acreditación de 2003}

Mediante carta de agosto 12 de 2003 dirigida al rector de la Universidad de los Andes, en ese entonces Carlos Angulo Galvis, el Consejo Nacional de Acreditación remitió el informe de evaluación externa realizado por los pares académicos, doctores Juan Oberto Sotomayor, Juan Manuel Campo Cabal y Germán Silva. ${ }^{65}$

El análisis cubre ocho factores, los cuales agrupan 42 características en total. Los ocho factores son:

1. Características asociadas a la misión y al proyecto institucional.

2. Características asociadas a los estudiantes.

3. Características asociadas a los profesores.

4. Características asociadas a los procesos académicos.

5. Características asociadas al bienestar institucional.

6. Características asociadas a la organización, administración y gestión.

65 Consultado en el archivo personal del autor. 


\begin{abstract}
7. Características asociadas a los egresados e impacto sobre el medio.
\end{abstract}

8 Características asociadas a los recursos físicos y financieros.

Si bien ya se hizo un breve comentario sobre lo establecido por los pares académicos, es necesario adentrarse en el contenido de su informe para analizar en detalle lo relativo a la estructura del currículo.

Al estudiar las características asociadas a los procesos académicos, y luego de describir la estructura general y las particularidades del currículo de pregrado el informe señala:

Por supuesto podrá estarse de acuerdo o no con la estructura de un plan de estudios como éste, pero lo que no puede negarse es su viabilidad y validez. Es más, de hecho los resultados del mismo son más que satisfactorios, pues el programa de Derecho de la Universidad de los Andes sigue produciendo egresados competentes, formados en la disciplina, críticos y con una reconocida capacidad para desempeñarse profesionalmente. ${ }^{66}$

Posteriormente, el informe refleja el proceso de tensiones que se inició desde la implementación de la reforma de 1997, en cuanto a qué contenidos y asignaturas debían hacer parte o no del ciclo de formación básica

Entendemos, no obstante que si bien existe más o menos acuerdo entre los profesores respecto de la estructura del plan de estudios (división por ciclos), la discusión respecto de

66

lbíd., p. 14. su contenido continúa abierta (...) Estimamos muy conveniente continuar con esta discusión, pues después de escuchar las diversas opiniones de los profesores quedó la sensación de que en algunos casos los contenidos de los ciclos obedecen más a una transacción entre los diversos puntos de vista que a un criterio académico claro. (...) En nuestra opinión, no se ha llegado todavía (sic) una adecuada conceptualización respecto de lo que debe entenderse por formación jurídica básica y por ende a un consenso respecto de las materias que deben integrar dicho ciclo. ${ }^{67}$

Esta visión de los pares académicos fue ratificada en sus recomendaciones finales para el mejoramiento de la calidad del programa, pero como una invitación a promover la discusión al interior de la Facultad sobre el contenido de las asignaturas que integran el ciclo básico, más nunca como sugerencia a reformar el currículo. ${ }^{68}$

\section{DE LA REGULACIÓN VERTICAL Y CENTRALIZADA A LA REGULACIÓN HORIZONTAL Y DISPERSA}

Como se explicó anteriormente, la reforma de 1997 fue fruto de una coyuntura nacional e internacional particular, en la cual los derechos a la autonomía universitaria y libertad de cátedra sirvieron como apoyo legal para buscar un cambio en la enseñanza del Derecho en la Facultad de los Andes. Más allá de este propósito, creo que también la Facultad buscó definir su perso-

\footnotetext{
67 Ibíd., p. 15.

68 Ibíd., p. 25
} 
nalidad y hacer explícita su posición política en cuanto a qué es el Derecho, qué es ser un buen abogado, y a quiénes puede y debe servir, tanto la disciplina como sus practicantes. Esto coincide con la opinión de Isabel Cristina Jaramillo, quien sostiene, analizando también el caso particular de la reforma a la enseñanza del Derecho en la Universidad de los Andes, que

(...) la proliferación de evaluaciones, críticas y reformas que ha habido en los diez últimos años se entiende mejor como una competencia entre distintas posiciones políticas sobre el Derecho y las Facultades de Derecho que como un proceso de progresivo avance hacia la excelencia. ${ }^{69}$

Se puede afirmar, entonces, que la autonomía universitaria y la libertad de cátedra permitieron que esa "competencia entre distintas posiciones políticas" se trasladara a otro foro. Antes, sin su consagración a nivel constitucional, la competencia política sobre qué era el Derecho y cómo se debía enseñar se daba en otro ámbito y a través de otros actores. Era el Estado quien mediante distintas normativas, como el Decreto 1221 de 1990, determinaba qué era el Derecho y cómo debía enseñarse. La Constitución de 1991 cambió esto y dio a las universidades una mayor libertad para diseñar sus programas y metodologías de enseñanza. Esta libertad implicó también que proliferaran programas de Derecho de baja calidad, lo que prendió las alarmas del Estado y lo llevó a regular con mayor

69 JARAMILLO SIERRA, I. De la técnica a la política en la evaluación y reforma de la enseñanza legal. En: Revista Al Derecho. Bogotá, 2008, p. 17. atención la calidad de los programas.

Esta libertad también impulsó cambios importantes en la identidad del Derecho y del abogado. En el caso de la Universidad de los Andes, como se explicó anteriormente, al menos en el marco de la reforma de 1997 varios profesores de cátedra sintieron que lo que la Facultad definía como "Derecho" en el nuevo currículo los descalificaba para continuar enseñando en el marco de esa nueva disciplina. En ese momento se presentó la competencia política descrita por Jaramillo años después. El contexto de los años 90, la planta profesoral, la posición y el apoyo personal del decano Cepeda y del rector de la Universidad permitieron que la lucha política se inclinara, si no totalmente, al menos levemente hacia determinado lado.

¿Qué hizo entonces que la balanza volviera a reacomodarse de acuerdo con otra distribución de pesos? Según los frutos de la investigación desarrollada para este artículo fueron varios factores. Desde un principio hubo una especie de "álter ego" en la personalidad de la Facultad, y si bien la reforma de 1997 se instauró, no se puede desconocer que ciertas transacciones y arreglos políticos permitieron que una visión del Derecho distinta a la propuesta por la reforma cohabitara al menos en forma latente. Como se ha demostrado, los ECAES y el proceso de acreditación parecieron operar como catalizadores para que ese "álter ego" pudiera retomar fuerzas y lograr los cambios curriculares del 2005, que si bien no fueron radicales sí resultaron significativos. 
Antes de los ECAES no existía ningún examen o método oficial que indicara qué Facultad producía los "mejores abogados". Ahora, estos exámenes, no solo miden qué Facultad logra este propósito, sino más importante aún, implícitamente establecen un modelo de abogado: aquel que puede responder de forma correcta más cantidad de un determinado número de preguntas redactadas por un grupo de profesores del Derecho de distintas Facultades, conformado por el ICFES. De esta suerte, el Estado ya no ordena a través de decretos qué enseñar y cómo enseñar; parcialmente esta función ha sido asignada a los profesionales de la disciplina que diseñan el examen, y en segunda instancia a las propias Facultades que al sentirse "malas", "equivocadas", "anormales" o por "debajo de la media", cambian sus sistemas de enseñanza para adaptarse al modelo de profesional determinado por Ios ECAES.

Si bien el exdecano Cifuentes niega actualmente que en la reforma al currículo del 2005 hubiera tenido que ver un simple deseo de obtener mejores puntajes en los ECAES, las actas y los documentos que soportan la reforma de dicho año indican lo contrario. ${ }^{70}$ Puede ser cierto que esta segunda reforma haya apuntado a otros objetivos, pero sin duda alguna los malos resultados en los ECAES fueron (y en mi opinión son) un motivo y al mismo tiempo un catalizador de Ios cambios. Los ECAES tienen un fuerte poder de atracción y, generalmente, cualquier tipo de

70 Entrevista con Eduardo Cifuentes, decano de la Facultad de Derecho de la Universidad de los Andes en el periodo 2005-2011. Bogotá, noviembre 15 de 2012. examen "objetivo" se entiende como una forma de evaluar resultados y gestión. Esto se ve ratificado por la opinión de la actual Ex Directora del Centro de Investigación y Formación en Educación de la Universidad de los Andes, Juny Montoya, quien cree que este tipo de exámenes son muy importantes para todas las universidades y la competencia por los resultados puede generar presiones sobre las distintas Facultades y los decanos que las lideran. ${ }^{71}$ Esto confirma la hipótesis de por qué los ECAES operan como un elemento capaz de restablecer rumbos y proyectos.

Los procesos de acreditación, por su parte, operan de manera distinta a los ECAES. De hecho, personas que trabajaron en estos procesos al interior de la Facultad, consideran que el propósito no es evaluar el contenido del currículo a la luz de un modelo particular de enseñanza. ${ }^{72}$ Comparto esta opinión por cuanto ratifica que los pares no recomendaron, en su momento, incluir determinadas materias o hacer cambios puntuales al currículo.

Lo que sí ocurrió es que el proceso de acreditación, a través de la autoevaluación realizada por la Facultad y los comentarios de los pares académicos que participaron en este, evidenció la tensión existente entre los distintos proyectos educativo/políticos que conviven en ella. Para los pares académicos lo preocupante era que el ciclo de formación básica (alrededor del cual

71 En entrevista realizada el 2 de noviembre de 2012.

72 Entrevista con Carolina Moreno, líder del comité de la Facultad de Derecho de la Universidad de los Andes para el proceso de reacreditación del año 2011. Bogotá, 9 de noviembre de 2012. 
realmente giró el debate) y las asignaturas que lo componían “(...) obedecen más a una transacción entre los diversos puntos de vista que a un criterio académico claro", por tanto, "no se ha llegado todavía a una adecuada conceptualización respecto de lo que debe entenderse por formación jurídica básica y por ende a un consenso respecto de las materias que deben integrar dicho ciclo"73. Esta transacción educativa/ política reflejada en la estructura del currículo, a juzgar por los comentarios de los pares académicos, pareciera haber generado una sensación de desorientación en la Facultad, expresada en una falta de identidad clara frente a la pregunta ¿qué es el Derecho?

Pareciera ser que las distintas respuestas a esa pregunta hubieran generado algún temor frente al resultado del proceso de acreditación. Ante este temor y la aparente necesidad de contar con un referente externo que le dijera a la Facultad qué es el Derecho realmente, el ECAES se erigió con gran fuerza y los bajos resultados se interpretaron como una señal de que algo se estaba quedando por fuera de la enseñanza básica o que algo se estaba haciendo mal.

En concepto de Carolina Moreno ${ }^{74}$, antes de que se instauraran los ECAES y se hicieran extensivos y "opcionales pero obligatorios" los procesos de acreditación, la "personalidad" y el proyecto político y educativo de cada Facultad era defi-

73 CONSEJO NACIONAL DE ACREDITACIÓN. Ob. cit., p. 15.

74 Líder del comité de la Facultad de Derecho de la Universidad de los Andes para el proceso de reacreditación del año 2011. Entrevista realizada en Bogotá, el 9 de noviembre de 2012. nido en su mismo seno con todos los debates a que esto pudiera dar lugar, tal como ocurrió con la implementación de la reforma de 1997. Luego, estos mecanismos empezaron a operar como medios para crear estándares "objetivos" sobre qué es el Derecho y cuál es el buen abogado. La particularidad de estos mecanismos (ECAES y acreditación), en comparación con la regulación estatal, es que ellos por sí solos no obligan a una Facultad a enseñar el Derecho de determinada forma o a responder la pregunta sobre qué es el Derecho, de cierta manera. Es la comunidad que practica el Derecho la que, en últimas, tiene el poder para decidir qué es el Derecho, y para juzgar y etiquetar a los que se apartan de la visión y definición mayoritaria.

La efectividad de estos mecanismos, que no se desprende de la obligatoriedad de la ley, está entonces en crear un modelo particular que puede ser medido a través de ciertas técnicas. El no encajar en ese modelo implica entonces una pérdida de prestigio para la Facultad frente a sus pares.

\section{CONCLUSIONES}

En la Universidad de los Andes el proyecto de una Facultad de Derecho distinta, con unos métodos de enseñanza novedosos y una visión diferente sobre qué es el Derecho parece haberse diluido en el tiempo. Si bien en el currículo actual se evidencian todavía algunas estructuras del currículo que emergió originariamente de la reforma de 1997 , este ha sufrido cambios importantes. De hecho, Juny Montoya considera que si el abogado Uniandino es hoy en día considerado distinto 
a los que forman otras universidades, lo es más por la Universidad y por los cursos básicos que son transversales a todas las carreras, que por alguna característica propia del currículo de la Facultad de Derecho.

De acuerdo con lo expuesto en este artículo, parece ser que si bien el Estado ya no regula directamente la enseñanza del Derecho, continúa haciéndolo por métodos más sutiles pero en todo caso efectivos para la limitación de la autonomía universitaria y la libertad de cátedra consagradas a nivel constitucional. En nuestro caso, la aspiración por definir autónomamente cómo enseñar el Derecho y qué es un abogado competente, fue truncada y absorbida por una visión que logró imponer sus estándares y calificar su proyecto educativo y político como neutro, aclarando que no provino del Estado sino de la percepción que tiene la mayoría de los profesionales del Derecho sobre sí mismos. Los exámenes ECAES fueron entonces un receptáculo de esa visión hegemónica, y en combinación con los procesos de acreditación crearon un contexto en el cual el prestigio de la Facultad frente a sus pares y competidores se impuso sobre el proyecto de formar un abogado diferente, educado a través de un currículo muy distinto al de las otras universidades.

La pregunta que permanece abierta es si el proyecto de un abogado distinto y una educación legal alternativa es aún viable. La consagración, al menos formal, de la libertad de cátedra y autonomía universitaria permiten pensar en dicha posibilidad, teniendo en cuenta que el poder para definir cómo enseñar y qué enseñar per- manece, por ahora, no en el Estado, sino en la misma comunidad académica. El reto entonces consistirá en hallar una visión alternativa que resulte seductora a esta comunidad en su totalidad o al menos en su mayoría, o en perseguir una agenda más ambiciosa aunque seguramente complicada, que implique trasladar esa capacidad de definición y juicio sobre qué es el Derecho y qué es ser un buen abogado a un foro en el cual sea la propia sociedad civil la que juzgue si esta disciplina y sus practicantes satisfacen las necesidades que les demanda la realidad del país.

\section{Bibliografía}

\section{Fuentes primarias}

UNIVERSIDAD DE LOS ANDES. CONSEJO ACADÉMICO. Acta No. 11-97 de 15 de mayo de 1997.

. CONSEJO ACADÉMICO. Acta No 13-97 de 29 de mayo de 1997.

. CONSEJO ACADÉMICO. Acta No. 14720028 de agosto de 2002. . CONSEJO ACADÉMICO. Acta No. 218-05 7 de abril de 2005. . CONSEJO ACADÉMICO. Acta No.222 de 200526 de mayo de 2005. . CONSEJO EJECUTIVO. Acta No 15-97 de 30 de julio de 1997. 
. CONSEJO ACADÉMICO DE LA FACULTAD

DE DERECHO. Acta No 14-2004 de agosto 25 de 2004.

. CONSEJO ACADÉMICO FACULTAD DE DERECHO. Acta 5-2005 15 de abril de 2005.

. FACULTAD DE DERECHO. Documento interno de trabajo "Antecedentes de la Reforma a la Enseñanza del Derecho". S. f.

. FACULTAD DE DERECHO. Documento interno de trabajo "Evaluación del Plan de Estudios del Programa de Derecho y propuesta de ajustes para el 2005-II". s. f.

\section{Normatividad}

COLOMBIA. Presidencia de la República. Decreto 1221 de 1990. Por el cual se aprueba el Acuerdo número 60 del 24 de mayo de 1990, emanado por la Junta Directiva del Instituto Colombiano para el Fomento de la Educación Superior -ICFES-, por el cual se determinan los requisitos mínimos para la creación y funcionamiento de los programas de Derecho.

- Asamblea Constituyente. Constitución Política de 1991.

. Presidencia de la República. Decreto 1403 de 1993. Por el cual se reglamenta la Ley 30 de 1992.

. Presidencia de la República. Decreto 837 de 1994. Por el cual se establecen los requisitos para notificar e informar la creación y desa- rrollo de programas académicos de pregrado y especialización de educación superior.

. Presidencia de la República. Decreto 2790 de 1994. Por el cual se dictan normas para la inspección y vigilancia de los programas académicos de pregrado de educación superior.

. Presidencia de la República. Decreto 1225 de 1996. Por el cual se reglamenta la publicidad y el registro de programas académicos de educación superior.

- Presidencia de la República. Decreto 807 de 2000. Por el cual se modifica el artículo 8 del Decreto 1225 de 1996.

. Presidencia de la República. Decreto 2802 de 2001. Por el cual se reglamentan estándares de calidad para programas profesionales de pregrado en Derecho.

. Presidencia de la República. Decreto 1373 de 2002. Por el cual se reglamentan los Exámenes de Estado de Calidad de la Educación Superior, ECAES, de los estudiantes de los programas de Derecho.

. Presidencia de la República. Decreto 2566 de 2003. Por el cual se establecen las condiciones mínimas de calidad y demás requisitos para el ofrecimiento y desarrollo de programas académicos de educación superior y se dictan otras disposiciones. 
Jurisprudencia

COLOMBIA. CORTE CONSTITUCIONAL. Sentencia

T- 492 de 1992. M. P.: José Gregorio Hernández Galindo.

\section{Páginas Web}

Sistema Nacional de Acreditación. Consejo Nacional de Acreditación. [En línea]. Disponible en: static.colombiaaprende.edu.co/cache/ binaries/articles-186359_lineamientos_2. pdf?binary_rand=6205.

Universidad de los Andes. [En línea]. Disponible en: http://www.uniandes.edu.co/la-universidad/informacion-general/mision

\section{Fuentes secundarias}

BELL LEMUS, Gustavo, PINZÓN DE LEWIN, Patricia, MORALES REGUEROS, Lorenzo y ROJAS ROA, David. Historia de la Universidad de los Andes. Bogotá: Universidad de los Andes, 2008, tomo I.

BOTERO BERNAL, Andrés. Autonomía universitaria. Desarrollo e impacto del concepto en CoIombia. Medellín: Universidad de Antioquia, 2005.

CEPEDA ESPINOSA, Manuel José. Los derechos y la interpretación de la Nueva Constitución. En: Revista de Derecho Público. Marzo, 1991, no. 1.

FUENTES HERNÁNDEZ, Alfredo. Educación legal y educación superior en Colombia: desarro-
Ilos institucionales y legales 1990-2002. En: Abogacía y Educación Legal. Disponible en: http://sistemasjudiciales.org/content/jud/ archivos/notaarchivo/434.pdf. Consultado el 19 de noviembre de 2012.

GARCÍA VILLEGAS, Mauricio, et al. Los abogados en Colombia. Bogotá: Universidad Nacional, Facultad de Derecho, Ciencias Políticas y Sociales, 2011.

JARAMILLO, Isabel Cristina. De la técnica a la política en la evaluación y reforma de la enseñanza legal. En: Revista Al Derecho. Bogotá, 2008.

MINISTERIO DE JUSTICIA Y DEL DERECHO. EI abogado en el tiempo de la gente: realidad y prospectiva de la enseñanza del Derecho en Colombia. Bogotá: Ministerio de Justicia y del Derecho, 1995.

MONTOYA, Juny. La reforma a la enseñanza del Derecho en la Universidad de los Andes. En: Cuadernos Unimetanos, no. 15 (noviembre 2008).

. The Case for Active Learning in Legal Education. Saarbrücken: VDM Verlag Dr. Müller, 2008.

OTERO CLEVES, Ana María y JIMÉNEZ ÁNGEL, Andrés. Cuarenta años innovando el Derecho: una mirada a la Facultad de Derecho de la Universidad de los Andes (1968-2008). Bogotá: Universidad de los Andes, 2010. 
REVELO REVELO, José N. Informe de evaluación externa con fines de acreditación, Programa de Derecho, Universidad de los Andes. Bogotá: Consejo Nacional de Acreditación, julio 17 de 2003.
UNIVERSIDAD DE LOS ANDES. FACULTAD DE DERECHO. Plan de Desarrollo 1995-2000. Bogotá: Uniandes, 1996. 